\title{
HOW TO COMBINE BARK, FIBULA, AND CHASM (IF ONE SPEAKS PROTO-TURKIC)?
}

Keywords: Turkic, linguistic reconstruction, etymology, comparative linguistics

\begin{abstract}
Numerous Tukic words with only partially coinciding meanings (cf. the title and the first paragraph of the article) are traced back to very similar or even identical Proto-Turkic stems in ESTJa, and for most of the stems two or even three phonetic variants are suggested. In this article an attempt at finding possibly clear reconstructs is made.
\end{abstract}

It is extremely interesting to see that a few very similar Proto-Turkic stems have been suggested in ĖSTJa for words of (really or apparently?) different meanings. Here are some examples:

(a) ${ }^{\star} k a v \sim{ }^{\star} k a b \sim{ }^{\star} k a g$ for Tksh.dial. kavuz 'husk (of grains)' $\sim$ 'empty ear (of a plant), ear without seeds' (V 173)

(b) ${ }^{\star} k a v \sim{ }^{\star} k a b \sim{ }^{\star} k a g$ for Middle Tkc. $k a b$ 'bark (of a tree)' (VI 7); Trkm. kov 'moulted snake skin' (l.c.)

(c) ${ }^{\star} k a v$ for Tksh. kavak 'poplar' (V 170)

(d) ${ }^{\star} k \bar{a} p \sim{ }^{\star} k \bar{a} b$ for Trkm. $k a \bar{b} b y k$ 'bark' (V 168)

(e) ${ }^{\star} k a v \sim{ }^{\star} k o v$ for Tksh. kaval 'shepherd's flute' (V 171), kaval kemiği 'fibula, calf bone' (l.c.), kovan 'smoothbore shotgun' (1.c.)

(f) ${ }^{\star} k o b$ for Azerb. kobu 'chasm, abyss' (VI 6) Old Tkc. koby 'hollow, empty' (l.c.) ${ }^{2}$

(g) ${ }^{\star} k a g \sim{ }^{\star} k o g$ (V 169) or ${ }^{\star} k a g \sim{ }^{\star} k a v$ (V 170) for Trkm. kak 'dry, parched' (V 218), Kzk. kav 'last year's grass' (V 169), Trkm. kov 'tinder, amadou' (VI 8), Tksh.dial. kova koga 'reed' (VI 10, 11).

1 The entire lexical material was excerpted from ĖSTJa, volumes V and VI, so that only volume and page numbers are given in brackets.

2 This Turkic word possibly is a source of Mo. gobi '1. semidesert; 2. the Gobi’ (VI 7; Lessing 357a). 
One cannot but pose some questions: Is it possible to connect for instance (a) with (b) because of their phonetic shape, or (e) with (f) because of their meaning 'empty'? Are (b) and (d) really different stems? Is kova 'reed' better derived from * $k o g$ 'dry' in (g) or from ${ }^{\star} k o b$ 'hollow' in (f)? If ${ }^{\star} k a v$ and ${ }^{\star} k a g$ (g) alternate with each other is it equally reasonable to assume an alternation of ${ }^{\star} k o v$ and ${ }^{\star} k o g$ that has, however, never been suggested? Can all the variants be reduced to one stem (or one root) only?, and so on.

This article is nothing more than an attempt at finding answers to only some of these questions.

To begin with, any reconstruct with PTKc. ${ }^{*}-v$ - is uncertain since this consonantic phoneme is an innovation in Turkic. True, some are inclined to accept a semispirantized pronunciation of PTkc. $b$, sometimes represented in the Turkological transcription by « $\beta\rangle$ (e.g. Räsänen 1949: 172; Ščerbak 1970: 106). The sound value of the respective rune in the Old Turkic alphabet might have positionally varied between a fricative $\beta \sim v$ and a stop $b$ (Erdal 1998: 139). Nevertheless, we usually do not accept simultaneous existence of both $b$ and $v$ at the phonological level. Therefore the alternation of ${ }^{*} k a v$ and ${ }^{*} k a b$ in ĖSTJa V, VI cannot be accepted. Hereinafter, the letter $\langle\mathrm{b}-\rangle$ will be used for this consonant to render its $b \sim \beta$ value (i.e. occlusive semi-fricative), whereas $\langle\mathrm{v}\rangle$ stands for the fricative $/ \mathrm{v} /$ that evolved from $b \sim \beta$ in the course of time. ${ }^{3}$

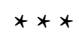

It is convenient at this point to deal with Tksh.dial. kavuz 'husk (of grains)' (VI 173). Since its Proto-Turkic stem could not possibly have been ${ }^{\star} k a v$, two possibilities remain in this context: ${ }^{*} k a b$ or ${ }^{\star} k a g$. There exists only one variant pointing to ${ }^{*}-g$, i.e. Tksh.dial. goğuz 'nutshell' (l.c.). However, it is hardly possible to accept its ProtoTurkic character since the - $g$ did not survive in any other Turkic language or dialect and, further, because the first syllable vowel - $o$ - (originating from - $a$ - labialized before $-v$ ) is clearly secondary and older than $-g$ : clearly this variant should be, on the whole, considered an innovation.

The evolution can be conceived in the following way: ${ }^{*} k a b\left(+{ }^{*}+y z\right)>{ }^{*} k a b y z$ $\left(\sim{ }^{*} k a b u z\right)>\operatorname{kavyz}\left(\sim \operatorname{kavuz}>{ }^{*} \operatorname{kovuz}>{ }^{\star} k \operatorname{koguz}>\operatorname{gog} u z\right)$. As can be seen, the one Proto-Turkic form ${ }^{\star} k a b$ suffices to explain all phonetic variants of $k a b y z$. We should

The difference between labiodental $v$ and bilabial consonantic $w$ (not $u$ !) that is sometimes reflected in Cyrillic-based Turkic notations in ESTJa can be ignored here because word-final $v$ generally is bilabial in Turkic, rather than labiodental. Even if the degree of bilabiality may vary in different languages this phonetic circumstance does not affect our etymological considerations.

4 Variants without asterisk are attested in ÈSTJa V 173. 
now test whether it suffices to explain also all the other words suspected of belonging to the same word family.

We begin our test with words denoting 'snake skin' 'bark (of a tree)': Trkm. kov 'moulted snake skin'; Middle Tkc. kab kav '1. id.; 2. bark; 3. nutshell'; Tksh.dial. kav '1. id.'; Tat.dial., Bašk.dial. kap (in: jylan kaby '1. id.'); Tobolsk-Tat. kap '1. id.; 4. shell, crust; 5. thin skin on seeds' (VI 7).

In VEWT 214b, Clauson 578b and TMEN III Nr. 1364, these words are considered to be successor forms of ${ }^{\star} k \bar{a} p$ 'vessel, small bag'. Now, barring the fact that attestations like MKašg. kabsa-, Trkm. kābsa- 'to surround, encircle' suggest PTkc. ${ }^{\star} k a \bar{b}$, rather than ${ }^{\star} k \bar{a} p$, the quantitative difference between ${ }^{\star} k \bar{a} p \sim{ }^{\star} k \bar{a} b$ 'vessel' on the one hand and ${ }^{\star} k a b$ 'bark; skin' on the other is conspicuous. ${ }^{5}$ The syntagm jylan kaby 'snake skin' might have originally suggested this connection, i.e. 'snake skin' < *'snake ( snake's) bag'. On the other hand, however, the meaning '(moulted) snake skin' might have equally well developed from jylan 'snake' + kab 'bark; skin; shell; crust', so that nothing actually points to the necessity of referring to ${ }^{\star} k \bar{a} p \sim{ }^{\star} k \bar{a} b$ 'vessel'.

Tksh. kavak 'poplar' has numerous equivalents in other Turkic idioms, mostly designating some specific sorts of trees, e.g. Tksh.dial. kavak' plane tree', Armeno-Kipč. xabax (terak'i) 'mulberry tree', Tat.dial. kuvak 'nut-tree', Tuv. $x \bar{a} k$ 'willow', and also Čag. kuvak 'bush(es), shrub(s)' (V 170).

All these words are certainly to be somehow connected with Tksh.dial. kavla

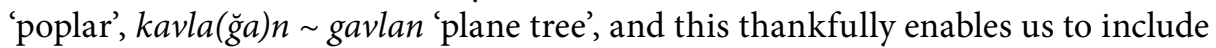
another word into this group, i.e. Tksh.dial. gavlăgan 'species of tree, characterized by “moulting” its bark' (V 170sq.), that surely goes back to ${ }^{\star} k a v l \bar{a}-$ (> Tksh.dial. kavla(l.c.) 'to peel, to shed leaves/bark') $<{ }^{\star} k a v<{ }^{\star} k a b$ 'bark; skin'.

Thus, we have found some further words that can all be explained as derivatives of the same stem ${ }^{\star} k a b$ : Tksh. kavak $\left(\sim\right.$ Cag. kuvak) $<{ }^{\star} k a v a k<{ }^{\star} k a v\left(<{ }^{\star} k a b\right.$ 'bark; skin') > [a] ${ }^{\star} k a v+u l$ - 'to shed/lose the bark' $>{ }^{\star} k a v u l-a>$ Tksh.dial. kavla; [b] ${ }^{\star} k a v+l \bar{a}->$ 'to shed/lose the bark' $>{ }^{\star} k a v l \bar{a}-$ gan $>$ Tksh.dial. kavlağan $\sim$ gavlağan. Unfortunately, there is no basis on which to assess which of the tree names first evolved from the meaning 'tree "moulting" its bark'.

The only feature that can cast some doubt on the original identity of ${ }^{\star} k a b$ 'bark' and Trkm. ka abyk id. is the vowel length. A secondary lengthening of low vowels

5 Čuv. xup 'bast (of a lime-tree)' does not settle the problem of long vowels either, cf. Ceylan (1997: 145): " “*ā foneminin Çuvaşçada $u, \imath, \breve{\imath}$ ile gösterilmesinin ünlü uzunluğu ile ilgisi yoktur. Çünkü kısa * $a$ fonemi de aynı biçimde gösterilmektedir”. 
in syllables directly preceding a syllable with a high vowel is, however, a frequent tendency in Turkic. Since there are no other attestations suggesting long-vowel reconstruction of this Proto-Turkic stem, there is nothing for it but to accept the secondary lengthening, i.e. ${ }^{*} k a b$ 'bark' $>{ }^{\star} k a b y k>$ Trkm. $k \bar{a} b y k$ id. ${ }^{6}$

The next word, noted here symbolically as kaval, is represented by the following specific forms: Tksh.dial., Gag. kaval 'a hollow object' = Tksh.dial., Gag., Crimean Kar., Tat.dial. kaval, Tksh.dial. goval, Nog. kabal 'shepherd's flute' = Čuv. kaval 'horn, clarion' = Tksh.dial., Azerb. kaval 'tambourine' = Tksh.dial. gaval kovan 'smoothbore shotgun', Balk. kaval 'flintlock' = Tksh. kaval 'a stupid/shallow person' (V 171).

The following features of this word can be observed:

- Its distribution, practically limited to Western Turkic languages only, is conspicuous.

- This word occurs in five different phonetic forms from among which kaval is the most often attested one.

- Four out of five variants turn up in Turkish dialects.

- Three out of five variants turn up exclusively in Turkish dialects.

- Čuv. kaval is phonetically identical with (and semantically similar to) Tat.dial. kaval, so that it most probably is a Tatar loanword.

This distribution suggests that kaval possibly is a lexical innovation spreading from Anatolia or, at least, a Western Turkic regionalism.

The stem ${ }^{*} k a v \sim{ }^{*} k o v$ 'hollow', suggested in ĖSTJa V 171, seems to be a good starting point for the modern semantic range. Of special interest is the semantic connection of these words with Tksh.dial. kaval kemiğ i 'calf bone, fibula' (lit. 'kaval bone'). If the word kaval denotes 'hollow' or a 'hollow object' 'tube' the syntagm is rather expected to be ${ }^{*} k a v a l$ kemik in Turkish, i.e. lit. 'hollow bone' or 'a bone that is a hollow object; «hollow object(-like) / tube(-like) bone»' (cf. Tksh.dial. kaval tüfek 'smoothbore shotgun', lit. 'tube(-like) shotgun', ĖSTJa V 171). This objection should compel us to treat the syntagm with caution. Thankfully, the phrase kaval kemiği is perfectly correct if one interprets it (somewhat grimly, I grant) as 'a bone suitable for a flute'. Or maybe just a 'flute bone'? Interestingly enough, the Latin term tibia means both 'shinbone' and 'pipe, flute'. Similarly, the Slavic word ${ }^{*}$ piščals $\left(<{ }^{*} p i s k e ́ l b\right)$ 'pipe, flute' > 'shinbone' has inter alia the following modern reflexes: Pol. piszczel 'shinbone' piszczałka 'pipe', Slovene piščál '1. pipe; 2. shinbone', Old Russ. piščál' 'a type of shotgun' dial. 'pipe' (Boryś 2005: 438). The Slavic example legitimates the question of the direction of the semantic change in Turkic: 'fibula' > 'pipe, flute' or 'pipe, flute' > 'fibula'.

6 The semantic function of the suffix ${ }^{*}+y k$ is unknown in this case. It has become a customary practice to ascribe a diminutive function to such suffixes. However, it is also possible to assume that the suffix was originally used to mark a (fine?) distinction between two different sorts of bark.

7 It should, of course, be ${ }^{\star} k a b \sim{ }^{\star} k o b$. 
The variant ${ }^{\star} k a b$ was suggested above as the etymon of words pivoting on the meaning 'bark (of a tree)'. Therefore it would be more convenient to connect the meaning 'hollow' with ${ }^{\star} k o b$, which, however, is by itself not a sufficient argument. Since both - $o$ - and - $a$-occur in this word family, and also because it is limited to the Western Turkic languages only, the conjecture suggests itself that this word results from a regional contamination of two originally different stems.

The problem of the original shape of the stem vowel becomes even more interesting if one also adduces attestations cited in the sixth volume of ESTJa: Trkm., Azerb. kov 'tinder, amadou' (VI 8) and Tksh.dial. kova 'bot. reed, cane' (VI 10). In the kova entry one can also find some examples of galvanic effect: Bašk. kyv 'dry (grass, tree)' kyvga 'last year's grass' kyva 'dead standing trees, dead wood' (VI 10). Whereas kov and kova point to a PTkc. ${ }^{*} k o b$, the Bašk. word kyv and so on points to ${ }^{\star} k a b$, rather than to ${ }^{\star} k o b$ (the $a \sim y$ alternation being quite common in the Turkic languages). But 'tinder' (kov) should usually be dry - just like grass or dead trees $(k y v, k y v g a)$. If one accepts the hypothesis that all Bašk. meanings go back to the Proto-Turkic sense 'dry' one is able to connect them also with kov 'tinder' which can be made of bark, esp. of birch bark whose inner layers always stay dry. It seems also possible (albeit not absolutely necessary) to connect the 'reed' with the Baškir words, if one interprets it as 'dry reed stems (used e.g. for mats, baskets or thatches)'.

Let us go back to the previous volume of ĖSTJa (V 169) again where we find yet another useful entry: Kzk., Tat.dial., Bašk. kav 'dry, last year's grass' = Oyr. $k \bar{u}$, Khak. $x \bar{u}$ 'dead standing tree' (and some other secondary meanings like Kirgh. $k \bar{u}$ 'paralysed' and so on). There can be no doubt: The Bašk. words above (VI 10) and the ${ }^{\star} k a v$ entry (V 169) belong together, and they were unnecessarily separated by the editors.

Moreover, our new word is attested in the following phonetic forms: $k a v \sim k y v$, $k o u, k u v, k \bar{u} \sim x \bar{u}$ for which a Proto-Turkic stem ${ }^{\star} k a g \sim{ }^{\star} k o g$ is suggested on page 169 and ${ }^{\star} k a g \sim{ }^{\star} k a v$ on page 170 . Reference to yet another stem, namely ${ }^{\star} k a k$, involves us in an even greater complication than one might be inclined to suppose because it is, on top of everything else, represented by two separate entries: kak 'dry, parched' $k a k$ - 'to dry' (V 218) and kak 'dried-up lake' (V 220). ${ }^{8}$

Barring all other phonetic variants and semantic changes that make the picture even more complex but do not seem to change it substantially, three groups of words can be distinguished here. They reflect three originally different stems which were, of course, phonetically modified in the course of time:

The fact that kak also denotes a more or less ordinary lake, and not a dried-up one, in some languages can probably be ignored because a semantic evolution ('dried-up lake' [MKašg.] > 'a small hollow resultant from dried-up morass' [Kirgh.] > 'rain-water accumulated in hollows or rock holes' [Tksh.dial.] 'a new mountain meadow' [Tksh.dial.] and so on) seems easily imaginable. 


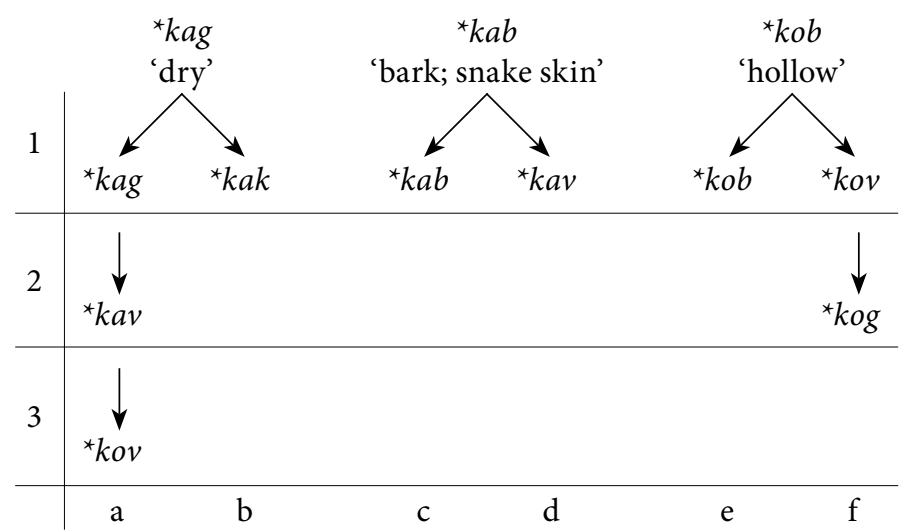

The table only shows evolutionary stages. ${ }^{\star} k o v(3 \mathrm{a})$ and ${ }^{\star} k o v(1 \mathrm{f})$, as well as ${ }^{\star} k a v(2 \mathrm{a})$ and ${ }^{*} k a v(1 d)$, may have very well existed side by side in one and the same epoch. It is even almost certain, given the fact that some words can only be explained by contamination (see below) of phonetic variants placed at different levels in this table.

Examples:

${ }^{\star}$ kag

${ }^{\star} k a g(1 \mathrm{a})$ :

No examples survived

${ }^{\star} k a k \pm(1 \mathrm{~b})$ :

Trkm. kak 'dry, parched' (V 218)

Uyg.dial. kak- '(trans.) to dry' (V 218)

MKašg. kak 'dried-up lake' (V 220)

${ }^{\star} k a v$ (2a):

Kzk. kav 'last year's grass' (V 169)

Bašk. kyv 'dry (grass, tree)' (VI 10)

Bašk. kyvga 'last year's grass' (VI 10)

Bašk. kyva 'dead wood' (VI 10)

${ }^{\star} k o v(3 \mathrm{a})$ :

Trkm. kov 'tinder, amadou' (VI 8)

\section{${ }^{\star} k a b$}

${ }^{\star} k a b(1 \mathrm{c})$ :

Middle Tkc. kab 'bark' (VI 7)

Tksh. kabuk, Trkm. kābyk 'bark' (V 168)

${ }^{\star} k a v$ (1d):

Tksh.dial., Ott., Bašk. kav 'moulted snake skin' (VI 7)

\section{${ }^{\star}$ kob}

${ }^{\star} k o b(1 \mathrm{e})$ :

Tksh.dial., Crimean Kar. koba 'cave' (VI 5)

Azerb. kobu 'chasm' (VI 7) 
${ }^{*} k o v(1 \mathrm{f})$ :

(?) Tksh.dial. kova 'reed, cane' (VI 10)

MKašg. kovuk 'hollow, empty' (VI 5)

${ }^{\star} \operatorname{kog}(2 \mathrm{f})$ :

(?) Tksh.dial. koga 'reed, cane' (VI 11)

Ott. koguk 'hole (in a rock, a tree, a tooth)' (VI 5)

A situation in which languages that are in constant contact with each other (and this was the standard situation in Central Asia for centuries) have at their disposal stems of very similar or even identical phonetic shape (like ${ }^{\star} k a v$ in $2 \mathrm{a}$ and $1 \mathrm{~d}$, or ${ }^{\star} k o v$ in 3a and 1f) will of course easily lead to contaminations, especially because $g \sim v$ and $b \sim v$ alternations are quite common in these languages.

This probably is the case with Tksh. and Gag. kaval 'shepherd's flute' (V 171) that has also its -o-equivalents: Tksh.dial. goval 'reed pipe, flute' (l.c.) and Tksh. dial. kovan 'smoothbore shotgun' (l.c.). Oddly enough, the - $a$-variants predominate here, even if their meanings pivot on 'hollow' and thus clearly point to ${ }^{\star} k o b$, not to ${ }^{\star} k a b$.

There can be also hardly any doubt that Tksh.dial. kaval kemiği 'fibula, calf bone' has little in common with 'bark' 'snake skin' or 'dry'. This word will surely represent a next step in the semantic evolution of 'pipe' (<'hollow'). Nevertheless, formally it, too, displays an $-a$-.

The idea of kaval's having resulted from a contamination corresponds pretty well with the fact that this word family is restricted to Western (first of all, South Western) Turkic, and not common in the entire Turkic linguistic world.

Also Tksh.dial. kavuz 'empty ear (of a plant); husk (of grains)' (V 173) belongs to the same group. A contamination of ${ }^{\star} k o b$ 'hollow' and ${ }^{\star} k a b$ 'bark; skin' could easily produce a new stem ${ }^{\star} k a b$ 'husk'.

There is no clear connection between 'tinder' (kov) and 'hollow' ( $\left.{ }^{\star} k o b\right)$ but no other stem in this context (i.e. neither ${ }^{\star} k a g$ nor ${ }^{\star} k a v$ ) has $-o$-. Again, this word, too, might be a result of contamination of ${ }^{\star} k a v(1 \mathrm{~d})<{ }^{\star} k a b$ 'bark' or ${ }^{\star} k a v(2 \mathrm{a})<{ }^{\star} k a g$ 'dry' with a variant with $-o$ - like ${ }^{\star} k o v$ in (3a) or (1f). On the other hand, exactly this word can be also interpreted as a result of a common labialization: $k o v<{ }^{\star} k a v(2 \mathrm{a})$. At present, no argument can be offered to settle the problem. ${ }^{9}$

\footnotetext{
The numerous words involved here have produced such a tangled situation that this article can only be a first attempt at disentangling it. Some aspects have not been even mentioned here. This is the case for instance with Kzk. kopa 'a place overgrown with reed or carex' (VI 10) - a word that is for certain somehow connected with Tksh.dial. kova 'reed, cane' (l.c.) but the difficulty of explaining its voiceless - $p$ - is compounded by the existence of Kzk. koga 'a sort of lake reed' (l.c.) (incidentally, called also in Russian (<Tkc.): $\kappa y z a)$, i.e. exactly a Kzk. variant with a voiced intervocalic consonant. - Another question is whether kavak (kemiği) belongs together with ${ }^{\star} k a v a=k o v a$ 'reed' because another word for 'fibula' in Turkish is kamış kemiği, lit. 'reed bone'.
} 
No definite recipe can be presented to those who wish to combine bark, fibula and chasm. It seems, however, certain that the Proto-Turkic language provided its daughter languages with two instruments that made such an evolution possible: a set of phonetically similar stems and two alternations affecting consonants of these stems. The daughter languages, for their part, managed to be spoken in adjacent territories. Affecting each other and borrowing from each other were under such conditions inevitable.

\section{References}

Clauson = Clauson G. 1972. An etymological dictionary of pre-thirteenth-century Turkish. Oxford.

ÈSTJa V = [Sevortjan È.V.], Levitskaja L.S., Dybo A.V., Rassadin V.I. 1997. Ėtimologičeskij slovaŕ tjurkskich jazykov. [vol. V: $\kappa, \kappa]$. Moskva.

ÈSTJa VI = [Sevortjan È.V.], Blagova G.F., Levitskaja, L.S., Dybo A.V., Rassadin V.I. 2000. Ėtimologičeskij slovaŕ tjurkskich jazykov. [vol. VI: $\kappa$ (misprinted for: $қ$ )]. Moskva.

Lessing = Lessing F.D. 1960. Mongolian-English dictionary. Berkeley, Los Angeles.

TMEN III = Doerfer G. 1967. Türkische und mongolische Elemente im Neupersischen unter besonderer Berücksichtigung älterer neupersischer Geschichtsquellen, vor allem der Mongolen- und Timuridenzeit. [vol. III]. Wiesbaden.

VEWT = Räsänen M. 1969. Versuch eines etymologischen Wörterbuchs der Türksprachen. Helsinki.

Boryś W. 2005. Słownik etymologiczny języka polskiego. Kraków.

Ceylan E. 1997. Çuvaşçada çok zamanl ses bilgisi. Ankara.

Erdal M. 1998. Old Turkic. - Johanson L., Csató É.Á. (ed.) The Turkic languages. London, New York: 138-157.

Räsänen M. 1949. Materialien zur Lautgeschichte der türkischen Sprachen. Helsinki.

Ščerbak A.M. 1970. Sravnitel'naja fonetika tjurkskich jazykov. Leningrad. 